ORIGINAL RESEARCH

\title{
Changes in Vitamin Status of Indian Antarctic Expeditioners During a One-Month Stay in Austral Summer
}

Praveen Vats, PhD; Som N. Singh, PhD; Vijay K. Singh, D Pharma; Radhey Shyam, MSc; Tribhuvan N. Upadhyay, PhD; Shashi B. Singh, PhD; Pratul K. Banerjee, PhD

From the Defence Institute of Physiology and Allied Sciences, Timarpur, Delhi, India.

\begin{abstract}
Objective.-Antarctic expeditioners face extremes of environmental conditions along with isolation which affect normal human activity at a polar station. Diets of polar expeditioners consist of products that have been kept in storage for more than a year. Processing and preservation adversely affect the nutritive value of the food products, especially water-soluble vitamins. This study was conducted to determine water-soluble vitamin status of Antarctic expeditioners consuming processed canned food.

Methods. - Twenty-two healthy male volunteers age 26 to 56 years $(39.5 \pm 8.5$, mean $\pm \mathrm{SD})$ participated in the study. The study was conducted in 3 phases: at Goa, India (phase I), 48 hours after arriving in Antarctica (phase II) and after 1 month in Antarctica (phase III). Water-soluble vitamin status in erythrocytes was assessed at each phase with evaluation of riboflavin, thiamine, and pyridoxine status. Urinary $N$-methyl nicotinamide and methylmalonic acid (MMA) levels were measured to assess niacin and vitamin $\mathrm{B}_{12}$ status. Blood plasma assays were used to assess ascorbic acid status.

Results.-No significant changes in riboflavin, thiamine, and pyridoxine status in erythrocytes and urinary excretion levels were observed after 1 month in Antarctica. Vitamin C levels decreased significantly $(P<.001)$ after 1 month in Antarctica compared with basal values $(1.31 \pm 0.076 \mathrm{mg} / \mathrm{dL}$ during phase I to $0.81 \pm 0.063 \mathrm{mg} / \mathrm{dL}$ during phase III). However, these levels were still within the normal reference range.
\end{abstract}

Conclusion.-This study found no water-soluble vitamin deficiencies in participants consuming processed and canned food after 1 month in Antarctica.

Key words: processed food, transketolase, glutathione reductase, aspartate aminotransferase, ascorbic acid

\section{Introduction}

Antarctica presents an inhospitable environment that challenges the metabolic processes in the body. The challenging environmental conditions in Antarctica are extreme low temperature, high wind velocity, low humidity, snowstorms, long polar days and nights, high levels of ultraviolet radiation, magnetic storms, and increased ionization.

Acclimatization to a new environmental condition leads to changes in caloric expenditure and intake. Energy expenditure increases with cold exposure, and more calories are required to meet these increased requirements. ${ }^{1}$ Askew (1995) reported that a higher quantity of

Corresponding author: Dr. Praveen Vats, Defence Institute of Physiology and Allied Sciences, Lucknow Road, Timarpur, Delhi 110054 India (e-mail: vatsp2001@ rediffmail.com).
$\mathrm{B}$ vitamins is required to meet the increased demand in stress conditions to sustain metabolism. ${ }^{1}$ Reports about increased requirements of thiamine, riboflavin, and pyridoxine under environmental stress, excessive physical work, and decreased physical performance during deficiency are controversial. ${ }^{2-7}$ Vitamin $\mathrm{C}$ is an excellent water-soluble antioxidant with a strong reducing potential. Because of its scavenging properties, it is expected to help provide antioxidant defense by countering the stress of cold. It is reported that vitamin $\mathrm{C}$ accelerates thermogenesis and protects against cold and cold injury. ${ }^{8-11}$

It is also reported that storage and processing cause loss of water-soluble vitamins in food items. ${ }^{12-14} \mathrm{Be}-$ cause the diet of Antarctic expeditioners consists of canned fruits, fruit juices, frozen meat, fish, poultry, and other frozen, canned, and dehydrated items that have 
been kept in storage for more than a year, Antarctic expeditioners may be at risk for low dietary deficiency of water-soluble vitamins.

Vitamins are essential for metabolic functions and their deficiencies could lead to a decrease in physical performance. Relatively higher turnover rate with inadequate intake can lead to biochemical changes followed by clinical symptoms of deficiency. Studies are lacking about the status and changes in circulation of water-soluble vitamins during an Antarctic stay. Hence, we conducted this study to determine the water-soluble vitamin status of Antarctic expeditioners while consuming processed and canned food.

\section{Materials and methods}

The study was conducted during Austral Summer from December to February on 22 healthy male volunteers of the Indian Antarctic Expedition. Participants were 26 to 56 years old $(39.5 \pm 8.5$, mean $\pm \mathrm{SD})$. The participants weighed 49 to $76 \mathrm{~kg}$ with heights of 157.3 to $185.3 \mathrm{~cm}$. Written consent for participating in the study was obtained from the participants after an explanation of the protocol approved by the Defence Institute of Physiology and Allied Sciences (Delhi, India) Ethics Committee.

The study was conducted in 3 phases. Initial baseline data were collected at Goa, India (phase I). After phase I, study participants were taken to Cape Town (South Africa) by air and on a 9-day sea route to Antarctica thereafter. Measurements were again taken 48 hours after arriving in Antarctica (phase II) and after a 1-month stay in Antarctica (phase III). During the study, ambient temperatures were $24^{\circ} \mathrm{C}$ to $35^{\circ} \mathrm{C}$ at phase $\mathrm{I}$ and $-9.2^{\circ} \mathrm{C}$ to $5^{\circ} \mathrm{C}$ during phases II and III. During the sea voyage, participants consumed mostly fresh food and some canned food, whereas in Antarctica, most of the food items were packed as canned food. Participants had free access to food items, but took no vitamin or mineral supplementation.

To estimate average caloric intake, duplicate plate samples were taken randomly at various times (viz, breakfast, lunch, and dinner) from the participants for analysis. Total energy expenditure was computed by recording the 24-hour activities of the participants with the Time and Motion Study method. ${ }^{15}$ In this method, participants were asked to record their 24-hour activities for a period of 1 week on a time and motion form issued to them. The energy cost of each task performed by participants was based on earlier studies of the Defence Institute of Physiology and Allied Sciences. ${ }^{16,17}$

Blood samples were collected at all phases, whereas urine samples were collected in phases II and III only.
Blood samples were collected between 7 and 9 AM from the antecubital vein after an overnight fast. Plasma was separated immediately after blood collection and stored at $-20^{\circ} \mathrm{C}$. Red blood cells (RBC) were washed with 150 $\mathrm{mM}$ potassium chloride $(\mathrm{KCl})$ and stored at $-20^{\circ} \mathrm{C}$. For urinary excretion studies, 24 hours of urine was collected with $\mathrm{HCl}$ as preservative in phases II and III.

Erythrocyte glutathione reductase (GR) activity for riboflavin status and transketolase activity for thiamin status were measured by methods described by Bamji. ${ }^{18,19}$ Erythrocyte aspartate aminotransferase (AST) activity for vitamin $\mathrm{B}_{6}$ status was assayed by the method of $\mathrm{Ca}$ band et al. ${ }^{20}$ Urinary thiamin and riboflavin levels were estimated by the methods described by Varley et al. ${ }^{21,22}$ Urinary $N$-methyl nicotinamide for niacin and methylmalonic acid (MMA) for vitamin $\mathrm{B}_{12}$ status were measured with the methods of Huff and Perlzweig ${ }^{23}$ and Giorgio, ${ }^{24}$ respectively. Ascorbic acid in plasma was assayed by the method of Zannoni et al. ${ }^{25}$

\section{STATISTICAL ANALYSIS}

The data obtained in different phases of the study were analyzed by repeated measures 1-way analysis of variance and a post hoc test by the least significant difference method. Comparisons were made in prestimulation activity levels of transketolase, GR, and AST and for plasma vitamin C levels between different phases. Data for prestimulation and poststimulation activities were analyzed with a paired Student's $t$ test. Data for urinary excretion of thiamin, riboflavin, $N$-methyl nicotinamide, and MMA, between phases II and III were analyzed with a paired Student's $t$ test, for which $P<.05$ was considered significant.

\section{Results}

The daily average energy intake during phases II and III was $16.35 \pm 1.29 \mathrm{MJ}$, whereas the average energy expenditure was $13.04 \pm 1.98 \mathrm{MJ}$, with a positive energy balance of $3.31 \mathrm{MJ} / \mathrm{d}$ per person. An average increase of $2.15 \mathrm{~kg}$ and $1.03 \mathrm{~kg}$ in body weight was observed between phases I and II and phases II and III, respectively. The total average weight gain by the participants between phases I and III was $3.18 \mathrm{~kg}$.

Erythrocyte transketolase activity was similar in all phases of the study. An approximately 13\% increase in erythrocytes transketolase activities was observed after stimulation with thiamine pyrophosphate in phase I. However, the increase was not statistically significant. In phase II, although the activity coefficient was the same as in phase I, the increase was statistically significant, 
Table 1. Erythrocyte transketolase activity in different phases $\dagger$ at Goa and in Antarctica

\begin{tabular}{|c|c|c|c|}
\hline Transketolase & Phase I & Phase II & Phase III \\
\hline Activity, $\mu \mathrm{M} \cdot \mathrm{mL} \mathrm{RBC}{ }^{-1} \cdot \mathrm{h}^{-1}$ & $11.53 \pm 0.57$ & $11.20 \pm 0.41$ & $10.97 \pm 1.07$ \\
\hline Activity after TPP stimulation, $\mu \mathrm{M} \cdot \mathrm{mL} \mathrm{RBC}^{-1} \cdot \mathrm{h}^{-1}$ & $13.02 \pm 0.47$ & $12.71 \pm 0.47 *$ & $12.25 \pm 0.66$ \\
\hline Activity coefficient & 1.13 & 1.13 & 1.11 \\
\hline
\end{tabular}

whereas in phase III, the increase was not statistically significant (Table 1).

Erythrocyte GR activity levels were significantly lower in phases II and III compared with phase I $(P<.001)$. An activity coefficient of 1.54 was observed in erythrocyte GR activities after in vitro stimulation with flavin adenine dinucleotide (FAD) in phase I, whereas in phases II and III, activity coefficients were 1.22 and 1.61, respectively (Table 2). The increases in GR activities after FAD stimulation were statistically significant in all the phases compared with prestimulation activity of the respective phase.

No significant change in AST activity was observed in erythrocytes of participants in Antarctica. An approximately $60 \%$ increase was observed in AST activity after stimulation with pyridoxal 5'-phosphate (PLP; activity coefficient 1.60) in phase I of the study. However, the activity coefficient for AST activity after PLP stimulation in phases II and III was only 1.49 (Table 3). The increases in AST activities after PLP stimulation were statistically significant in all phases compared with prestimulation activities of the respective phase.

No significant changes were observed in urinary excretion levels of thiamin, riboflavin, $N$-methyl nicotinamide, and urinary MMA after a 1-month stay in Antarctica (phase III) compared with phase II (Table 4).

Lower levels of plasma ascorbic acid were observed in phase II and phase III of the study compared with phase I (sea level). The changes were significant only in phase III (i.e., after a 1-month stay in Antarctica) when compared with sea level values $(P<.001$; Table 5).

\section{Discussion}

Water-soluble vitamins, with the exception of folic acid and vitamin $\mathrm{C}$, are involved in the oxidation and conversion of food to energy and in the functioning of the Krebs cycle. Thus, an adequate nutritional status with respect to the water-soluble vitamins becomes essential for the production of sufficient energy for thermogenesis and for physical exertion while working and residing in a cold environment such as Antarctica.

In this investigation, we assessed the adequacy of thiamin nutrition through tissue saturation status, taking into consideration the transketolase activity in erythrocytes and urinary excretion of thiamin. Erythrocyte transketolase activity remained unaltered throughout the study period. The activity coefficient also remained almost the same in all phases of the study. The urinary excretion of thiamin was also well within the reference range during Antarctic residency for a period of 1 month. We conducted this study over 30 days with no sign of thiamin deficiency. Therefore, the data suggest

Table 2. Erythrocyte glutathione reductase activity in different phases $\dagger$ at Goa and in Antarctica

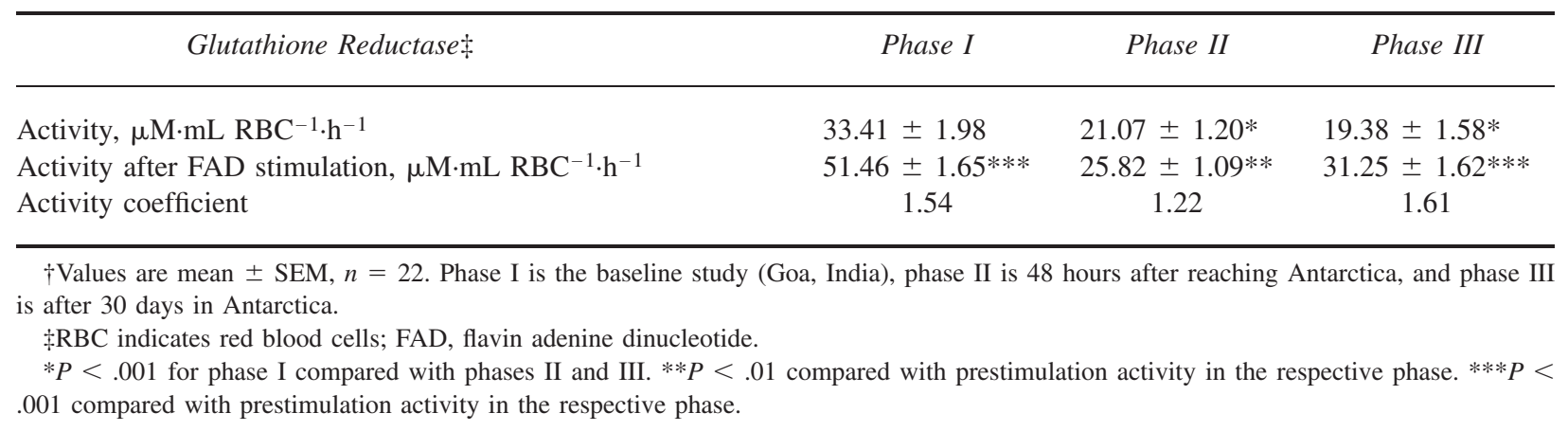


Table 3. Erythrocyte aspartate aminotransferase activity in different phases $\dagger$ at Goa and in Antarctica

\begin{tabular}{|c|c|c|c|}
\hline Aspartate Aminotransferase $\ddagger$ & Phase I & Phase II & Phase III \\
\hline Activity, $\mu \mathrm{M} \cdot \mathrm{mL} \mathrm{RBC}^{-1} \cdot \mathrm{h}^{-1}$ & $20.30 \pm 1.01$ & $18.80 \pm 0.94$ & $21.34 \pm 1.29$ \\
\hline Activity after PLP stimulation, $\mu \mathrm{M} \cdot \mathrm{mL} \mathrm{RBC}^{-1} \cdot \mathrm{h}^{-1}$ & $32.40 \pm 1.32 * * *$ & $28.10 \pm 1.22 * * *$ & $31.81 \pm 1.73 * * *$ \\
\hline Activity coefficient & 1.60 & 1.49 & 1.49 \\
\hline
\end{tabular}

that an adequate amount of thiamin was available in the food consumed by the expeditioners.

Riboflavin status was assessed by erythrocyte GR activity and by 24-hour urinary excretion of riboflavin. In this study, erythrocyte GR activity in phase II was decreased compared with phase I. In phase III, erythrocyte GR activity was also less compared with the basal value. These changes were statistically significant. Because conversion of oxidized glutathione (GSSG) to reduced glutathione (GSH) by GR depends on reduced nicotinamide adenine dinucleotide phosphate (NADPH), a decrease in GR activity could have been the result of decreased levels of NADPH as a result of cellular free radical stress under cold conditions. ${ }^{26}$ A decrease in GR activity under cold stress has also been reported in earlier studies by Kaushik and Kaur ${ }^{26}$ and Ohno et al. ${ }^{27}$

In normal conditions, in vitro FAD addition should increase the GR activity if it is low initially, but such a situation is not born out by the observations during the study. Surprisingly, the activity coefficients were decreased compared with the basal value. This state could not be explained. Because urinary excretion of riboflavin in phase II and phase III and the activity coefficient of GR on stimulation in phase III were within the reference range, it was concluded that riboflavin was not deficient. More detailed studies will be required to explain the reduced GR activities per se.

In this study, erythrocyte AST activity and its stimulation with PLP was assessed to monitor vitamin $\mathrm{B}_{6}$ status. Vitamin $\mathrm{B}_{6}$ acts as a cofactor for glycogen phosphorylase, which converts stored glycogen into glucose and has involvement in the conversion of various amino acids into oxaloacetate, as well as the conversion of $\alpha$ ketoglutarate, succinyl-CoA, and pyruvate into various amino acids. Thus, a pronounced deficiency of vitamin $\mathrm{B}_{6}$ would cause a decrease in the conversion of glycogen to glucose, depleting a major source of fuel. ${ }^{28}$ In this study a nonsignificant decrease in erythrocyte AST activity was observed in phase II. However, the activity coefficient after PLP stimulation decreased from 1.60 to 1.49 , and that was maintained in phase III. The percentage increase in AST activity through stimulation ranged from $49 \%$ to $60 \%$. This was well within the normal acceptable limits, which indicated the adequacy of $\mathrm{B}_{6}$ dietary intake.

Niacin status was assessed by estimation of 24-hour urinary excretion of $\mathrm{N}$-methyl nicotinamide. A deficiency of niacin could impair glycolysis and the Krebs cycle, whereas excessive niacin supplementation is reported to suppress the release of free fatty acids from adipose tissues through decreased lipolysis. Deficiency of niacin could result in decreased availability of a major fuel source for use during strenuous exercise. ${ }^{29,30}$ Excretion of normal levels of $\mathrm{N}$-methyl nicotinamide in this investigation confirmed sufficient intake of nicotinic acid through diet.

In this study, the excretion of MMA in 24-hour urine was used as an index of vitamin $\mathrm{B}_{12}$ status. The normal

Table 4. Urinary thiamin, riboflavin, $N$-methyl nicotinamide, and methylmalonic acid in different phases in Antarctica*

\begin{tabular}{|c|c|c|c|}
\hline & Phase II & Phase III & $\begin{array}{c}\text { Normal Reference } \\
\text { Range }\end{array}$ \\
\hline Thiamin, $\mu \mathrm{g} / 24 \mathrm{~h}$ & $96.70 \pm 9.51$ & $92.13 \pm 7.63$ & $50-500$ \\
\hline Riboflavin, $\mu \mathrm{g} / 24 \mathrm{~h}$ & $335.18 \pm 52.67$ & $293.81 \pm 37.27$ & $>120$ \\
\hline$N$-methyl nicotinamide, $\mathrm{mg} / 24 \mathrm{~h}$ & $3.20 \pm 0.26$ & $4.49 \pm 0.61$ & $3-17$ \\
\hline Methylmalonic acid, $\mu \mathrm{M} / 24 \mathrm{~h}$ & $48.70 \pm 4.56$ & $37.38 \pm 4.55$ & $0-210$ \\
\hline
\end{tabular}

\footnotetext{
*Values (mean $\pm \mathrm{SEM}, n=22)$ were not significantly different between the phases $(P>.05)$.
} 
Table 5. Plasma ascorbic acid levels in different phases at Goa and in Antarctica $\dagger$

\begin{tabular}{|c|c|c|c|c|}
\hline & Phase I & Phase II & Phase III & $\begin{array}{c}\text { Normal Reference } \\
\text { Range }\end{array}$ \\
\hline Ascorbic acid, mg/dL & $1.31 \pm 0.08$ & $0.99 \pm 0.07$ & $0.81 \pm 0.06^{* * *}$ & $0.4-2.0$ \\
\hline
\end{tabular}

reference range of 24-hour excretion of MMA is reported to be 0 to $93 \mathrm{mmol}^{31}$ However, the reference range varies from method to method. The observed values in this investigation were in the range of 37 to 48 $\mu \mathrm{mol}$ in 24 hours, which is considered within the reference range. MMA concentration did not change significantly in 24-hour urine during residence in Antarctica, and the excretion levels of MMA were well within the normal acceptable reference range, indicating the adequacy of vitamin $\mathrm{B}_{12}$ intake.

Plasma ascorbic acid levels were measured to assess vitamin $\mathrm{C}$ status in this study. Vitamin $\mathrm{C}$, because of its antioxidant properties and strong reducing potential, is reported to help in providing antioxidant defense by countering the stress of cold and hypoxia during exposure to high altitude. ${ }^{32} \mathrm{~A}$ decreasing trend of vitamin $\mathrm{C}$ concentration was observed in this investigation. The level of vitamin $\mathrm{C}$ in plasma was significantly lower after a 1-month stay in Antarctica compared with the basal level at Goa, but the reduced level was within the acceptable reference range.

Although values were within the normal reference range, it was expected that vitamin $\mathrm{C}$ levels would decrease because of cold stress. The protective thermogenic effect of vitamin $\mathrm{C}$ against cold and cold injury has been determined by many investigators. ${ }^{9,10,32,33}$ It has been reported that vitamin $\mathrm{C}$ accelerates thermogenesis, peripheral vasodilatation, and to an extent, sympathetic hyperactivity. ${ }^{8,33}$ The efficiency of vitamin $\mathrm{C}$ in potentiating a peripheral vascular response during cold acclimatization can be attributed to its antioxidant properties and major physiological functions, including metabolic and thermogenic properties, collagen synthesis, and antistress activity.

This study had several limitations. Energy intake and expenditure were not assessed at sea level. Levels of micronutrients in food consumed could not be assessed because of logistic problems. Knowledge of vitamin $\mathrm{C}$ intake levels would elucidate whether the decrease in plasma vitamin C level was due to lower intake or was due to increase in use because of the cold. With our data, it can be speculated that decreased levels of vitamin $\mathrm{C}$ in phase III could be due to the combined effect of cold and decreased intake of vitamin $\mathrm{C}$ through processed food.

\section{CONCLUSIONS}

Results of this study indicated that expeditioners maintained vitamin B and vitamin C status within acceptable biological reference ranges after 1 month in Antarctica in the Austral summer while consuming canned and processed food. The decrease in vitamin $C$ levels observed in this study during the Antarctic stay could be attributed to an increase in the metabolism of vitamin $\mathrm{C}$ because of its protective thermogenic effect against cold, a decrease in the intake of vitamin $\mathrm{C}$ from a lack of citrus fruits or fresh vegetables in the food supplied, or both.

\section{References}

1. Askew EW. Environmental and physical stress and nutrient requirements. Am J Clin Nutr. 1995;61:631S-637S.

2. Cohen J, Potosnak LL, Frank O, Baker H. A nutritional and haematological assessment of elite ballet dancers. Physician Sports Med. 1985;13:43-54.

3. Weight LM, Noakes TD, Labadarios D, Graves J, Jacob P, Berman PA. Vitamin and mineral status of trained athletes including the effects of supplementation. Am J Clin Nutr. 1988;47:186-191.

4. Guilland JC, Penaranda T, Gallet C, Boggio V, Fuchs F, Klepping J. Vitamin status of young athletes including the effects of supplementation. Med Sci Sports Exerc. 1989; 21:441-449.

5. Van de Bedek EJ. Vitamins and endurance training: food for running or faddish claims? Sports Med. 1985;2:175197.

6. Belko AZ, Obarzanek E, Kalkwarf HJ, Rotter MA, Bogusz S, Miller D, Haas JD, Roe DA. Effects of exercise on riboflavin requirements of young women. Am J Clin Nutr. 1983;37:509-517.

7. Tremblay A, Boilard F, Breton MF, Bessette H, Roberge AG. The effects of riboflavin supplementation on the nutritional status and performance of elite swimmers. Nutr Res. 1984;4:201-208.

8. Beaton JR. Vitamin C metabolism in rats fed a low protein diet and exposed to cold. Can J Physiol Pharmacol. 1967; 45:335-342. 
9. Spillert CR, Hollinshed MB, Lazaro EJ. Protective effects of ascorbic acid on murine frostbite. Ann NY Acad Sci. 1987;498:517-518.

10. Iyenger J, George A, Russel JC, Das DK. Generation of free radical during cold injury and rewarming. Vasc Sugr. 1990;24:467-474.

11. Purkayastha SS, Chabra PC, Verma SS, Selvamurthy W. Experimental studies on the treatment of frostbite in rats. Ind J Med Res. 1993;98:178-184.

12. Pai ML. Influences of cooking on the nutritional value of food. Part IV: further data on thiamin, riboflavin and nicotinic acid contents of cooked foods. Ind J Med Res. 1958; 46:609-614.

13. Lyimo MH, Nyagwegwe S, Mnkeni AP. Investigations on the effect of traditional food processing, preservation and storage methods on vegetable nutrients: a case study in Tanzania. Plant Food Hum Nutr. 1991;41:53-57.

14. Williams PG. Vitamin retention in cook/chill and cook/hot hold hospital food services. J Am Diet Assoc. 1996;96: 490-498.

15. Passmore R, Durnin JV. Human energy expenditure. Physiol Rev. 1955;35:801-840.

16. Malhotra MS, Ramaswamy SS, Ray SN. Influence of body weight on energy expenditure. J Appl Physiol. 1962;17: 433-435.

17. Sridharan K, Mukherjee AK, Grover SK, Kumria MML, Arora BS, Rai RM. Assessment of nutritional status and physical work capacity of road construction worker at altitude of $2150-2570 \mathrm{~m}$ on two different ration scales. Nutr Rep Int. 1987;35:1269-1277.

18. Bamji MS. Glutathione reductase activity in red blood cells and riboflavin nutritional status in humans. Clin Chim Acta. 1969;26:263-269.

19. Bamji MS. Transketolase activity and urinary excretion of thiamine in the assessment of thiamin nutrition status of Indians. Am J Clin Nutr. 1970;23:52-58.

20. Caband P, Leeper R, Wrolewski F. Colorimetric measurement of serum glutamic oxoloacetic transaminase. Am J Clin Pathol. 1956;26:1101-1105.

21. Varley H, Gowenlock AH, Bell M. Determination of thiamin in urine by thiochrome reaction. In: Practical Clinical Biochemistry. Vol 2. 5th ed. London, UK: William Heinemann Medical Books; 1976:224-226.
22. Varley H, Gowenlock AH, Bell M. Determination of riboflavin in urine. In: Practical Clinical Biochemistry. Vol 2. 5th ed. London, UK: William Heinemann Medical Books; 1976:229-230.

23. Huff JW, Perlzweig WA. The fluorescent condensation product of N1-methyl nicotinamide and acetone. II. A sensitive method for the determination of N1-methyl nicotinamide in urine. J Biol Chem. 1947;167:157-167.

24. Giorgio AJ. The calorimetric measurement of urinary methylmalonic acid. In: McCormick DB, Wright LD, eds. Methods in Enzymology. Vol 18. Part C. New York: Academic Press; 1971:103-107.

25. Zannoni V, Lynch M, Goldstein S, Sato P. Rapid micro method for the determination of ascorbic acid in plasma and tissue. Biochem Med. 1974;11:41-48.

26. Kaushik K, Kaur J. Chronic cold exposure affects the antioxidant defense system in various rat tissues. Clin Chim Acta. 2003;333:69-77.

27. Ohno H, Kondo T, Fujiwara Y, Tagami S, Kuroshima A, Kawakami Y. Effects of cold stress on glutathione and related enzymes in rat erythrocytes. Int J Biometeorol. 1991;35:111-113.

28. Leklem JE. Vitamin B6. In: Machlin LJ, ed. Handbook of Vitamins. New York, NY: Marcel Dekker; 1991:341-392.

29. Carlson L, Havel R, Ekelund L, Holmgren A. Effects of nicotinic acid on the turnover rate and oxidation of the free fatty acids of plasma in man during exercise. Metabolism. 1963;12:837-845.

30. Bulow J. Human adipose tissue blood flow during prolonged exercise III. Effect of beta-adrenergic blockade, nicotinic acid and glucose infusion. Scand J Clin Lab Invest. 1981;41:415-424.

31. Giorgio AJ, Plaut GW. A method for the calorimetric determination of urinary methylmalonic acid in pernicious anaemia. J Lab Clin Med. 1965;66:667-676.

32. Purayastha SS, Sharma RP, Ilavazhagan G, Sridharan K, Ranganathan S, Selvamurthy W. Effect of vitamin C and $\mathrm{E}$ in modulating peripheral vascular response to local cold stimulus in man at high altitude. Jpn J Physiol. 1999;49: 159-167.

33. Wilson CWW. Vitamin C: tissue metabolism, over-saturation, desaturation and compensation. In: Brich GG, Parker KJ, eds. Vitamin C. London, UK: Applied Science Publishers; 1974:203-220. 